\title{
2 La EdUCACIÓN DEL SIGLO XXI. HACIA UN SISTEMA TECNOLÓGICO MULTIMEDIA. \\ LAS UNIVERSIDADES A DISTANCIA
}

Ricardo Marín Ibáñez

UNED

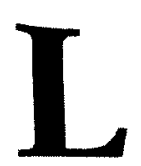

a ciencia consiste en colgar preguntas a las certidumbres más logradas. Y la primera convertir la afirmación del título en preguntas desazonadoras. ¿La educación del futuro será un sistema tecnológico multimedia? ¿En exclusividad? ¿Cómo integrará otros elementos, especialmente la presencia estimulante del profesor? ¿Será capaz el sistema educativo de seguir el ritmo vertiginoso y prodigioso del avance de las nuevas tecnologías de la información? ¿Cómo obtendremos de la tecnología todas sus virtualidades educativas? ¿Puede convertirse en un factor democratizador, igualador de la educación o va a servir para ahondar las diferencias ya existentes? ¿Pueden servir las universidades a distancia, y en nuestro caso la UNED, de laboratorio y ensayo de las tendencias que culminarán en el siglo XXI?

\section{EDUCACIÓN}

La educación es todo aprendizaje, humano, valioso e intencionado, pretende el pleno desarrollo de la persona, lo que implica su eficaz participación en el medio eco-socio-cultural. Lo demás, son sólo causas coadjuvantes, instrumentales. Educar es una tarea profundamente humana, hecha por perso- 
nas, para que cada cual, de un modo intencionado, alcance la cima de su personalidad. Se trata de forjar personalidades maduras, eficientes en su relación con su medio y con los demás, que sepan hacerse a sí mismas y a su entorno más valiosas. La persona educada amplía sus conocimientos, sus habilidades y actitudes encarnando los valores positivos. No sólo se comporta mejor, sino que es más. Píndaro, el cantor de los juegos olímpicos, trazó el ideal humano y educativo: "Llega a ser lo que eres".

Todo lo que no contribuye a ese despliegue y plenitud personal, todo lo que reduzca $o$ aplaste la personalidad no es educativo. La técnica ofrece posibilidades ilimitadas de información, de comunicación personal (uno de los grandes objetivos educativos), o, por el contrario, de avasallamiento y de degradación. La llamada telebasura es un ejemplo cotidiano. Somos nosotros los responsables. Los instrumentos valen según el uso que hagamos de ellos. Tanto a los que se muestran temerosos de los avances, como a los que proclaman que resolverán los problemas, en especial los educativos, hay que recordarles que el uso de la técnica y capacidad humanizadora o deshumanizante es exclusiva responsabilidad del hombre.

\section{LA PREVISIÓN DEL FUTURO}

A lo largo de toda la historia, adivinar el futuro ha sido el más apasionante, incierto, y a veces bien retribuido ejercicio profesional. En un mundo en cambio vertiginoso, donde cualquier previsión queda pronto superada, es una aventura de incierto resultado. Desde el primer computador, hace ya más de medio siglo, hasta los de la última generación (que pronto será penúltima), el cambio es tan acelerado, los progresos tan espectaculares, que superan lo que decenios atrás se atrevieron a imaginar los visionarios más audaces.

Quien no se compromete a forjar el futuro es sobrepasado por la historia, se convierte en prehistoria.

La época postindustrial es la de las comunicaciones. De la sociedad de producción y distribución de bienes se ha pasado a la de información. La Comisión Europea (1996) define la sociedad actual como la de "del aprendizaje", que sobrepasa con mucho la escuela.

Cada época de la historia, cada edad de la vida y cada pueblo, destaca una de las tres dimensiones temporales, si bien nunca puede olvidarse del todo alguna.

Si la infancia es puro presente sensomotriz, la vejez se recrea en un pasado que con el buril de los días cinceló su ser. Los mayores aseguran que ellos 
estaban mejor formados y tenían un comportamiento más ético que los jóvenes hoy.

La juventud es esencialmente futurizante. Le preocupa su porvenir, lo que será, quiere anticipar la vida antes de vivirla y le angustia no saber exactamente lo que es, porque ignora lo que será.

Nuestro tiempo ha magnificado la juventud, todos quieren ser jóvenes. El vestido desenfadado, las actitudes audaces y un cierto incompromiso con lo que ellos no han forjado es el común denominador de casi todas las manifestaciones culturales. Como dice Javier Zubiri en Naturaleza, Historia, Dios, estamos pendientes del porvenir, para el pasado apenas si tenemos tiempo ni humor.

Los chinos dicen que: "Profetizar es muy difícil, especialmente cuando se trata del futuro". Del porvenir nada podemos asegurar rotundamente como verdadero o falso. A pesar de esto, todos hablamos del futuro y anticipamos lo que acontecerá, generalmente es lo que está de acuerdo con nuestros sentimientos, deseos, esperanzas y temores. A lo largo de toda la historia, sin desmayo, el hombre ha sentido una curiosidad y una necesidad irreprimible de saber lo que iba a acontecer.

Los adivinos han gozado de prestigio en todas las culturas. En el imperio romano había colegios profesionales para desvelar el porvenir: los arúspices analizaban las entrañas de las víctimas y los augures lo leían en el vuelo de las aves. Dejemos que los nigromantes evoquen a los muertos y que los astrólogos analicen las conjunciones astrales. La bola de cristal, las cartas o las rayas de la mano aún siguen dando juego.

Pero cuando hay que tomar graves decisiones hay que superar el estadio de los sueños anticipados y enfrentarse metódicamente al problema.

La prospectiva consiste en un conjunto de métodos aplicados a los campos más variados para preparar decisiones de largo alcance.

Hay que distinguir entre "prever" lo que puede acontecer, frente a disponer las cosas para alcanzar un objetivo (prevenir). La previsión se basa en estimaciones probabilistas.

La educación es esencialmente prospectiva por ser un proceso de larga duración. En el plano individual, se va concretando en la programación de cuanto hay que realizar para que el sujeto pase de lo que es, a lo que puede y debe ser. En la orientación personal, académica y profesional, se realiza, junto al diagnóstico, el pronóstico y se establece el plan de acción para optimizar la situación actual. 
El futuro no sobreviene de un modo fatal, inevitable. La naturaleza con su determinismo podría permitir anticipaciones casi seguras. El caso de la astronomía es paradigmático. A medida que se dan más complejos factores es más difícil la previsión. Las predicciones meteorológicas no llegan más allá de una semana, pero ya es más difícil prever las reacciones personales o colectivas.

Las anticipaciones juegan un papel fundamental en economía, pero también en política y en la vida cotidiana. Construimos nuestro presente según las previsiones del futuro.

\section{LA FUTUROLOGÍA EN EL SIGLO XX}

No se trata de hacer la historia de la prospectiva, sino de registrar algunos de sus hitos.

La Organización de Cooperación y Desarrollo Económico (OCDE) cultivó el programa Interfuturos (1976-79). Se ha especializado en la previsión tecnológica y ha elaborado modelos matemáticos. En una de sus obras: La previsión technologique, se registran sólo en este campo decenas de métodos que permiten dar más altos índices de probabilidad a esta previsión. La UNESCO hace preceder de estudios prospectivos sus planes quinquenales. La Universidad de Syracuse y el Standford Research Institute han trabajado intensamente en la futurología. Herman Kahn y Anthony Wiener, en The Year 2000 (El año 2000), presentaron un centenar de innovaciones que se darían en el último tercio del siglo $\mathrm{XX}$, entre ellas, nuevas aplicaciones del láser, nuevos materiales y fuentes de energía, la fotografía tridimensional...

En Madrid el CENIDE (Ministerio de Educación) trabajó en la década de los '70 sobre prospectiva en el horizonte del año 2000.

Han sido numerosas las revistas destinadas a prospectiva y futurología. En la bibliografía recogemos algunas obras que en su día tuvieron un impacto extraordinario.

\section{TRES ENFOQUES PROSPECTIVOS}

Hay tres métodos fundamentales en prospectiva, en los que se integran todos los restantes: 1) extrapolación de las tendencias actuales, 2) trazar objetivos que movilicen la población hacia ellos, y 3) la consideración sisté- 
mica que permita integrar todos los elementos y variables, para que la previsión tenga mayores garantías.

4.1. El más tradicional es la extrapolación de las tendencias del presente. Es el enfoque "desde atrás hacia adelante", como el de quien sigue la trayectoria de la flecha disparada. Pedro Rosselló en su Teoría de las corrientes educativas detectó las corrientes en alza y predijo el futuro inmediato, analizando en la Oficina Internacional de Educación de Ginebra los datos aportados por los gobiernos a lo largo de un cuarto de siglo. Las previsiones demográficas aplican el método de la extrapolación.

La aparición inesperada de un factor puede invertir las tendencias. La píldora anticonceptiva frenó las previsiones de expansión demográfica. La bomba atómica pudo cambiar el signo de la guerra en favor de Alemania y aceleró su desenlace en el Japón. La caída del muro de Berlín sorprendió a los sociólogos y a los politólogos. Los fundamentalismos y los etnocentrismos parecían imposibles en una sociedad que camina hacia la democracia y la unificación de las culturas. La lucha contra el analfabetismo se está prolongando mucho más allá de todas las previsiones, como lo han constatado las "Conferencias Internacionales de Adultos" convocadas por la UNESCO en Elsenoor (Dinamarca) 1948, Montreal 1960, Tokio 1972, París 1985, Hamburgo 1997.

Recordemos las perspectivas de un progreso económico sin sorpresas, en los años 60, que pronto quedaron quebradas con la crisis del petróleo de 1973, o la confianza ilimitada en que el progreso tecnológico lo resolvería todo, mientras que hoy se alzan voces por doquier, clamando contra los excesos e imprevisiones de una civilización industrial que ataca la naturaleza, y puede convertir el mundo en tierra inhabitable.

La extrapolación de las tendencias actuales es relativamente fácil de aplicar cuando se trata del progreso tecnológico. No es aventurado predecir que aumentará la potencia, la velocidad y la complejidad de las funciones de las computadoras. Los expertos podrán establecer modalidades y fechas, al menos a corto y medio plazo, con una relativa seguridad. La ciencia y la tecnología mantienen un progreso casi seguro. Su historia se acumula en su presente y casi predetermina su porvenir. Es lo que se designa como la concepción lineal de la historia.

En 1965 Alvin Toffler inventó el término el "shock" del futuro. Es la desorientación que produce un cambio excesivo en un breve lapso de tiempo. Es la enfermedad del cambio. Se habla de la educación para el cambio, de preparar para el futuro, pero no se sabe cómo hacerlo. Mientras algunos desean febrilmente el cambio otros se oponen pertinazmente a él.

Dada la complejidad de la previsión del futuro nadie puede alardear de conocer con certeza el mañana, y menos en un mundo en cambio acelerado. 
Hoy se vive la transitoriedad de todo, hasta las amistades son más efímeras. Los jóvenes se juran amor eterno... mientras dure. Lo que cuesta hoy es comprometerse.

Frente a la burocracia se generaliza la "adhocracia". Son estructuras efímeras, grupos ad hoc (task force) que se constituyen para cumplir una función determinada y luego se deshacen. Se calcula que los dos tercios de fin de siglo trabajarán en estas condiciones. La Organización de Cooperación y Desarrollo Económico tiene una estructura flexible. La mayor parte de sus programas se llevan a cabo en periodos quinquenales, apoyados por una estructura administrativa que se forma para su adecuado desarrollo. De no recibir al final una evaluación positiva desaparecen para dar lugar a otros.

Las comunicaciones instantáneas funcionan a la milmillonésima de segundo. La ciencia, como decía Popper, es lo provisional para siempre. Los conocimientos son cada vez más perecederos. El analfabeto del mañana no es el que no sabe leer, sino el que no ha aprendido a aprender. Recuerdo en mi estancia como profesor visitante en Detroit un eslogan que todos aceptaban: lo único importante es dominar tres lenguajes: inglés, español y el informático. Lo decisivo es cómo buscar información, seleccionarla, interpretarla, aplicarla...

Anticipar y adaptar, dos verbos menos usados, hoy son capitales en educación. Cuando los cambios son más vertiginosos hay que prever futuros más remotos. El conductor que va a más velocidad necesita con mayor anticipación conocer las señales y tomar posiciones y precauciones. Cuanto mayor responsabilidad se tiene en la escala social, más se requiere prever el futuro más remoto. Así el obrero de la fábrica sólo tiene en cuenta lo que va a acontecer en el momento siguiente, pero el Consejo de Administración ha de prever la evolución del mercado a corto, medio y aun a largo plazo.

Según Ostwald Spengler en su obra famosa La decadencia de Occidente, las civilizaciones, como la vida personal, tienen un ritmo biológico: nacen, crecen y finalmente desaparecen. El italiano J.B. Vico, en el siglo XVIII, hablaría en sentido similar de "corsi e ricorsi". Ni el progreso es lineal, ni el futuro es necesariamente mejor.

Todos tememos las sorpresas desagradables, a veces trágicas, que se esconden tras los pliegues neblinosos del mañana.

4.2. Comprometerse con objetivos para el futuro. Éste es el enfoque "desde delante hacia atrás". Normalmente en cualquier proyecto personal o social, primero trazamos el objetivo y luego diseñamos el plan de acción para alcanzarlo, determinando los medios, los recursos y los tiempos necesarios. Éste es el paradigma de toda acción auténticamente humana. Se comienza deseando la situación futura, y luego seleccionamos los factores que nos llevarán a su posesión. 
El presente se construye desde el futuro. Antes de que el balón entre en la portería contraria el jugador ha anticipado su trayectoria, no siempre sumisa. El motivo, la causa final, antes de realizarse ha sido anticipada, querida, anhelada. Sólo podemos prever la conducta de los hombres y los pasos de la historia si somos capaces de otear un futuro valioso, que aclara y dinamiza el presente inestable. Para establecer lo que se llama "escenarios" del futuro, para precisar los perfiles del porvenir no hay como mirar en la bola mágica del corazón de los humanos, y más aún en los hirvientes deseos de la juventud.

Los sistemas educativos trazan sus finalidades y objetivos para que las nuevas generaciones logren un futuro individual y social más humano. La política educativa, la planificación y la programación escolar son ejercicios de prospectiva para diseñar lo deseable y actuar, con objeto de optimizar la realidad presente.

El futuro atrae como un imán. ¿Qué es lo que enciende el interés de las nuevas generaciones? En cualquier caso no quieren ser como la mujer de Lot convertida en estatua de sal por volver la vista atrás.

La escuela guarda silencio respecto al porvenir y abruma con datos del pasado. Se está mirando por el espejo retrovisor y así el riesgo del accidente se acrecienta.

Frente al seguro progreso tecnológico, cuando se contempla la vida humana el panorama cambia. El progreso no es claro y a veces estamos ante patentes regresos.

Los cambios de valores colocan a cada generación ante una encrucijada: o bien continúa y perpetúa los valores de la generación precedente, o bien establece una ruptura radical para autoafimarse contraponiéndose, o se decide por conquistar nuevos horizontes, en parte continuación de lo anterior, en parte rivales de los valores vigentes. El conflicto intergeneracional es una prueba de las rupturas en el mundo axiológico.

En las producciones humanas hay momentos que nos parecen insuperables. El Taj Mahal de la India, la Alhambra de Granada, el Quijote, el teatro de Shakespeare, la Monna Lisa de Leonardo de Vinci, las Meninas de Velázquez o la Sexta sinfonía de Beethoven, nos siguen maravillando, desde nuestra atalaya de finales del siglo XX. Aquí no cuenta el progreso lineal. En cambio la tecnología contemporánea de ellos merece apenas un ocasional recuerdo histórico.

La educación ha pretendido siempre el pleno, equilibrado, integral, desarrollo personal y la más eficiente inserción social. Pero el hombre no es un ser abstracto, desvinculado de su medio, encerrado en una torre de marfil. 
Ortega y Gasset colocó una de las piedras angulares de su pensamiento en esta sentencia: "Yo soy yo y mi circunstancia". Heidegger nos definía como ser-en-el mundo, (in der Welt Sein) y Aristóteles nos caracteriza como: animal político (zoon politikón). No hay modo de dar la espalda a nuestro ambiente ecosociocultural.

Quizá el rasgo más saliente que va a determinar la educación es el de que vivimos en la era tecnológica, todos hasta los habitantes de las zonas más atrasadas o los partidarios de un conservacionismo a ultranza de la naturaleza están pendientes y acomodan su vida a una tecnología que nos invade y, a pesar de todos sus riesgos, mejora nuestra calidad de vida.

Si hemos de vivir penetrados por la tecnología, la escuela no puede vivir de espaldas a ella, ha de prepararse para comprenderla y usarla de un modo eficiente y racional. En este sentido no hace falta ser un profeta, un adivino, ni practicar una rigurosa metodología prospectiva para afirmar que la educación del futuro será un sistema tecnológico.

¿Estamos ante una auténtica revolución de la educación? ¿El paradigma del profesor en el aula, que ha sido el modelo multisecular del que todavía no nos hemos liberado, va a dar paso a otro en el que un sistema multimedia sustituirá al profesor y entregará a los "medios" todas las funciones docentes? ¿Basta contemplar el imparable progreso tecnológico para diseñar la escuela del futuro? ¿Es suficiente perfilar el "escenario" que parece desprenderse de las virtualidades de la tecnología y especialmente de la computadora? ¿Qué otras realidades hay que tener en cuenta para no dislocar la imagen del futuro?

En cualquier caso los ideales indican una línea de tensión hacia el futuro. He aquí algunos, que nadie discute.

4.2.1. Ideales que dirigen las tendencias. Los ideales políticos, libertad e igualdad, han sido un "leit motiv" constante a lo largo de dos últimos siglos, al menos en occidente. El artículo 1 de la Declaración de los derechos de hombre y del ciudadano de la Revolución Francesa (1989), inspirada en la Declaración de Independencia de los EEUU (1776), dice así: "los hombres nacen y permanecen libres e iguales en sus derechos". Y el artículo 1 de la Declaración universal de derechos humanos, de las Naciones Unidas (1948), afirma: "Todos los seres humanos nacen libres e iguales en dignidad y derechos". En el ámbito educativo, la igualdad se ha traducido en el siglo XX en el principio de igualdad de oportunidades. Se demanda esa igualdad no sólo en el acceso al sistema educativo sino también para permanecer y progresar en él, lo cual es ya mucho más comprometido. Sin embargo nadie quiere renunciar a este ideal, todos dicen apoyar en él su política educativa. Cualquier desigualdad levanta oleadas de protestas unánimes. Pero sin el apoyo de las nuevas tecnologías de la información que llevan a la escuela 
materiales didácticos de gran valor en apoyo de la tarea docente y son capaces de atender a toda la población en el ámbito extraescolar, tal principio queda en una generosa e incomprometida declaración.

4.2.2. Todos defienden la educación permanente. El Consejo de Europa en una obra clásica L'éducation permanente (1970) declara que este principio orientará su política educativa y que es el signo que adquirirá la educación en el siglo XXI, como la universalización de la enseñanza primaria ha sido el inspirador de la educación del siglo XX. Y ese mismo año la UNESCO creaba en su seno la división de "Educación Permanente".

Intentar ampliar la educación a más población, durante más años de escolaridad con los sistemas presenciales, y en años de restricciones y crisis económicas, es una utopía. Pero las nuevas tecnologías de la información, vencedoras del tiempo y del espacio, permiten una difusión ilimitada de los mensajes.

Tenemos graves necesidades educativas, las nuevas tecnologías de la información encierran asombrosas posibilidades, que de hecho alcanzan a toda la población sin limitaciones espacio-temporales. ¿Por qué no aprovechar sus inmensas virtualidades? Si un mensaje televisivo o de Internet está disponible para todos, ¿qué impide una masiva utilización para que la educación sea una realidad universal?

\subsection{CONSIDERACIÓN SISTÉMICA}

Si no contemplamos todos o, al menos, los principales factores y su mutua influencia, difícilmente podremos llegar a conclusiones que nos permitan despejar el velo que cubre ese tentador futuro que nos incita y se nos oculta.

La integración sistémica de ambos factores, los científico-tecnológicos y los humanísticos o, si se prefiere, el progreso tecnológico y el humano no son fáciles de conciliar. La ingeniería genética, la energía atómica y la invasión de la teleinformática que puede convertir todo lo privado en público están grávidas de posibilidades insospechadas, y a la vez son peligros que no auguran necesariamente un desenlace feliz.

En la educación coinciden todos los factores: materiales y espirituales. Esto obliga a un enfoque sistémico inevitable. El hombre es un microcosmos. Todas las zonas de la realidad están representadas en él. Y la educación tiene que desplegar todas las dimensiones típicamente humanas.

El enfoque interdisciplinar aparece en el quicio de los movimientos innovadores. Una obra clave es L'interdisciplinarité (1972), con la que la OCDE impulsó esta corriente. El equipo que descubrió los restos de los primeros 
homínidos en Atapuerca, y que ha recibido el premio Príncipe de Asturias de investigación en 1997, es un ejemplo brillante de fecundidad intedisciplinar.

Si conociéramos todos los factores determinantes de los acontecimientos y su respectivo influjo, como se ha pretendido con el "análisis de sendas" (path analisis), podríamos dibujar escenarios fiables del futuro. Pero tanto la exhaustividad de los factores como su mutuo influjo son tareas arriesgadas, pues en la historia hay que contar con la libertad del hombre, ese factor que rompe los determinismos y nos enfrenta con lo original y lo insólito.

\section{EL MÉTODO DELFOS}

Elegimos el método Delfos a título de ejemplo, intentando establecer un cierto rigor metódico en la perturbadora selva del futuro. En él se ponen en juego los tres procedimientos prospectivos: extrapolación de tendencias, detección de ideales que anticipan el porvenir y el enfoque sistémico.

El método Delfos lo crea la Rand Corporation en Santa Mónica, junto a Los Ángeles (EE.UU.). Sus iniciadores, que ya dieron al método su rigor en 1952, fueron O. Helmer, E. S. Quade y N. Dalkey.

Se trata de consultar a los expertos, en grupo pero a distancia. No se reúnen ni trabajan juntos. La comunicación normal es telemática, aunque inicialmente fue por correo y teléfono. Su objetivo es la progresiva aproximación de las previsiones del grupo. El coordinador integra todas las aportaciones, las expone y elimina los valores extremos.

En cada ronda -generalmente son cuatro o cinco- se van aproximando las fechas y se va logrando la convergencia.

Los especialistas son numerosos y de carácter interdisciplinar. Contemplar la realidad de un modo unilateral lleva a desconocer muchos factores, con lo cual las predicciones son más inexactas.

En 1964, se constituyeron 6 grupos. Elegimos esta fecha porque ya se ha podido comprobar el grado de exactitud de sus anticipaciones. Se realizaron 4 consultas a un ritmo bimensual. El número de participantes fue de 80 , la mitad eran de la Rand Corporation. Había también expertos de otros países que hicieron más de 200 previsiones.

A un grupo se le encargó que se formularan todas las innovaciones que previsiblemente aparecerían en el medio siglo inmediato: se registraron 49. Hubo una gran coincidencia en 10 cuestiones. Se ordenaron todas las fechas y a partir de la segunda ronda se ofrecían sólo 3 valores: la mediana o valor 
central, el cuartil inferior (debajo del cual estaba el 25\% de los casos) y el cuartil superior (debajo del cual quedaban el $75 \%$ ). A la cuarta ronda se había producido un acuerdo razonable en 31 cuestiones. He aquí algunos ejemplos que muestran la eficacia del método. La fecha central es la más probable para que aparezca tal innovación, la primera indica que antes de ella no se alcanzará, y la tercera es el tope máximo en que ya gozaremos de su hallazgo.

- Previsiones meteorológicas casi seguras, 1973, 1975, 1988.

- Reemplazamiento de órganos del cuerpo humano por trasplante o síntesis, 1967, 1972, 1983.

- Control de deficiencias hereditarias, 1990, 2000, 2010.

- Constitución de un depósito central de informaciones con posibilidad de rápido acceso, 1972, 1975, 1990.

- Traducción automática de lenguas, 1970, 1975, 1978.

En ocasiones cada participante se autovalora sobre el grado en que se siente experto en cada cuestión.

Cuando alguien solicita información complementaria antes de tomar una decisión, el coordinador se la ofrece. Las previsiones han sido preferentemente en tecnología, pero también en los campos socioeconómico, cultural y político.

Hay algunos datos que se reiteran. La distancia entre el cuartil primero y el tercero es similar a la que hay entre la fecha en que se hace la previsión y la mediana. La distancia entre el primer cuartil y la mediana suele ser la mitad de la que hay entre la mediana y el tercer cuartil. Por ejemplo, un acontecimiento previsto en el año 2000, cuya mediana está en el año 2030, el primer cuartil se situará probablemente en torno al año 2020, y el tercero en el año 2050.

Cuando hay un interés pronunciado por una innovación, los plazos se reducen. Lo que suele ocurrir con las cuestiones militares y en tiempo de guerra, como aconteció con la bomba atómica.

El momento clave y decisivo es el de la elección de expertos, para lo cual hay que disponer de un fichero actualizado sobre los mejores especialistas en el campo. Los cálculos matemáticos para agrupar las respuestas son sencillos, pero el valor de las razones y hasta su agrupación requiere una especial preparación y buen tino en el coordinador.

Hay una constatación interesante: el grado de acierto está en razón inverSa a la lejanía de la fecha prevista. Lo cual indica que el futuro cuanto más 
remoto más incierto, pero todo cuanto permita pasar de la mera aleatoriedad a una mayor probabilidad debe ser utilizado. En el futuro se decidirá nuestra propia existencia y todas las precauciones metódicas para determinar su evanescente perfil son pocas.

\section{LOS RASGOS DE LA EDUCACIÓN A DISTANCIA COMO CLAVES PARA OTEAR LA EDUCACIÓN DEL SIGLO XXI}

Una de las tendencias más vigorosas e innovadoras es la educación a distancia. Los tres procedimientos prospectivos, antes enumerados, descubren en ella los caminos del futuro.

Seleccionamos, como un sector poderoso en alza, las universidades a distancia. Su expansión sostenida, espectacular, en el último tercio del siglo XX, es un buen indicador del poder productivo de la extrapolación de una tendencia expansiva. Recordemos sólo las primeras: OPEN University Británica (1969); Universidad Nacional de Educación a Distancia (España, 1972); Feruniversität (Alemania, 1974); Everyman's University (Israel, 1974), Allama Iqbal Open Universty (Pakistan, 1974); Athabasca University (Canadá, 1975)... La expansión de su alumnado sigue un ritmo sostenido. La UNED española comenzó con once mil alumnos y un cuarto de siglo después tenía más de 160.000. La tendencia expansiva, es clara, imparable.

Además ellas responden a los ideales de igualdad de oportunidades, de educación permanente y de las exigencias de una economía de escala, superando los límites tempoespaciales y sociológicos y las constricciones económicas. Puede responder, por una parte, a una demanda global, ya inevitable, y, por otra, a una adaptación a los intereses y a las circunstancias personales. Cada cual estudia aprovechando cualquier tiempo y lugar propicio, sin depender del estrecho, y a veces remoto, recinto del aula.

Vamos a analizar los elementos del complejo sistema tecnológico en que consisten las universidades a distancia, con especial referencia a la UNED.

\section{LA TECNOLOGÍA EDUCATIVA EN LOS SISTEMAS MULTIMEDIA DE EDUCACIÓN A DISTANCIA}

7.1. La técnica es el conjunto de procedimientos y recursos de que se sirve una ciencia o arte. Habitualmente entendemos por tal los aparatos fruto de los descubrimientos científicos. El progreso de las ciencias y la invención de nuevos artificios ha contribuido al progreso acelerado. Nos interesan espe- 
cialmente los instrumentos destinados a la comunicación de mensajes y, de un modo más concreto, a las nuevas tecnologías de la información.

Las técnicas utilizadas en educación, en general, han tenido un común denominador: mandar los mensajes a alguien separado por el tiempo o el espacio. La escritura marca el hito divisorio de la prehistoria a la historia. La imprenta, a mediados del siglo XV, difundió los manuscritos y popularizó el acceso a las obras maestras. Una de sus primeras realizaciones fue la famosa Biblia de Gutenberg en 1444. La prensa desde el siglo XVIII ha permitido recoger y difundir la información diaria. El teléfono desde el último cuarto del siglo XIX pone en contacto de un modo directo, inmediato, bidireccional, auditivo, a dos personas y ha sido explotado desde siempre para funciones tutoriales, por ello fue un instrumento que se incorporó a la enseñanza a distancia desde el primer momento.

En el siglo XX los recursos audiovisuales han llamado insistentemente a las puertas de la escuela, con desigual acogida.

\subsection{LOS RECURSOS AUDIOVISUALES MASIVOS}

Se los ha designado de formas variadas: medios de comunicación social, medios masivos de información, y también con la expresión inglesa "mass media". Este concepto comprende fundamentalmente: prensa, radio, audiocasete, televisión, vídeo...

7.2.1. La radio. Nace en los primeros años del siglo XX y no tardó en aprovecharse para fines didácticos. En 1923 se realizaron las primeras experiencias en España. Su empleo ha sido universal.

Por su economía y versatilidad ha sido utilizada en todos los niveles educativos, en todas las áreas de conocimientos y en las funciones más variadas. La encontramos desde la alfabetización hasta la Universidad. Su uso más frecuente ha sido para sustituir al profesor y alcanzar a una población alejada de las escuelas, pero también para facilitar informaciones de calidad a Centros de enseñanza con deficientes recursos personales y materiales. Así para la enseñanza de idiomas o la música.

La UNED española ha recurrido a ella desde su comienzo, hace ya un cuarto de siglo. Un tercio de los alumnos sigue las emisiones regularmente. En la actualidad la UNED emite un programa diario de dos horas y media durante todo el curso escolar, excepto en vacaciones, a través de Radio Nacional de España, y que cubre todo el ámbito nacional. Son unas 400 horas anuales, sólo superadas por la Universidad del Aire de Japón y la Open University británica. El programa lo llevan a cabo técnicos del medio y los profesores universitarios. Las tres modalidades más empleadas son: la entre- 
vista, el coloquio y la lección magistral. Si se tiene en cuenta que las disciplinas impartidas por la UNED superan las 1400, apenas sobrepasa el cuarto de hora el tiempo que teóricamente corresponde a cada una. Lo cual revela que, pese a su valor y al reconocimiento que recibe, no es pieza esencial en el sistema. Su valor es complementar el material impreso. En cambio en otros casos, como la Emisora Cultural Canaria (radio ECCA), juega un papel decisivo.

7.2.2. Cuando el magnetófono permitió grabar los mensajes sonoros, entre otros los de la radio, y darles permanencia y repetición ilimitada, se tuvo un instrumento que aprovecharon los sistemas educativos. Bates, de la Open University británica, llegó a decir que es el medio con más posibilidades de expansión de cara al futuro. En la UNED su uso es más limitado. Aparte de la totalidad de las emisiones por radio, ya grabadas, que superan las ocho mil horas, se han hecho otros audiocasetes específicos para las diversas materias y cuya cifra es más modesta, pues suman 80 en el año 1996.

7.2.3. Televisión. Desde los años cincuenta la televisión se viene empleando en educación. Su aparición levantó oleadas de entusiasmo. Con ella las actividades del aula podían llevarse a cualquier parte. Cada vez que ha aparecido una nueva tecnología de la información, se ha pensado que podía cambiar y transformar la enseñanza. La televisión educativa desató todas las esperanzas. En la década de los sesenta las investigaciones se contaron por millares. Las conclusiones fueron sorprendentes. Aproximadamente una cuarta parte descubrió que salían ganando los alumnos, supliendo al profesor con la televisión educativa, otra cuarta parte demostró que el profesor en la clase presencial era insustituible y los alumnos aprendían más con el sistema tradicional. En la mitad los resultados fueron similares, pues no alcanzaron el nivel de diferencias estadísticamente significativas. ¿Ocurrirá algo similar cuando dispongamos un volumen parecido de investigaciones referidas al ordenador?

Los primeros programas televisivos de la UNED comenzaron tardíamente en el curso escolar 1991-92, en colaboración con Telemadrid, en el programa "A saber". En los cursos siguientes se mantuvo una colaboración semanal en el canal 2 de televisión española, con el programa educativo "La aventura del saber". Desde comienzos de 1996, a través del canal Clásico de televisión española, que utiliza el sistema de satélites Hispasat, la UNED ha transmitido una hora diaria de lunes a viernes, repitiendo el sábado lo más interesante de toda la semana. A partir del presente curso 1998-99, la UNED vuelve a transmitir en la 2 de TVE, los viernes de 10,30 a 11,00 horas, y los sábados y domingos de 9,00 a 9,30 horas.

El formato es variado: coloquios, mesas redondas, exposiciones, debates, prácticas de laboratorio... que responde a los contenidos de las carreras. Los viernes se dedican a temas culturales y educativos de actualidad.

7.2.4. El vídeo da permanencia a los mensajes visuales y permite grabarlos y reproducirlos con una facilidad y economía muy superiores a la televi- 
sión. La UNED, aparte de la grabación de sus emisiones de televisión, ha elaborado un centenar de vídeos, algunos de los cuales han merecido premios internacionales.

Falta por realizar una investigación global sobre el coste-beneficio de estos medios.

\subsection{LOS RECURSOS TELEMÁTICOS}

Transmiten la información (datos, voz, imágenes) por vía terrestre o satélite, que en el caso del sistema digital se convierten en una secuencia de "bits", es decir, en una cadena de ceros y unos.

7.3.1. La videoconferencia. Es como una televisión interactiva. El profesor en la Sede Central y los alumnos en sus respectivos centros tienen la sensación de estar en la misma aula. La videoconferencia utiliza la Red Digital de Servicios Integrados (RDSI) de la Compañía Telefónica de España; comenzó en 1993. Transmite sonido, imagen, letras y cifras. La velocidad básica de la RDSI es de $64 \mathrm{kbps}$, para la videoconferencia. La cantidad de información que se puede enviar por segundo es de $128 \mathrm{kbps}$ (es decir, equivalente a dos llamadas telefónicas).

Puede constituir un equipo autónomo o integrado en un ordenador (sistema deskstop).

En 1996 la Red Educativa de Videoconferencia de la UNED es la mayor de Europa dedicada la educación. Consta de medio centenar de equipos, tres en la Sede Central y el resto en toda la geografía nacional.

Se han realizado ya más de 300 sesiones, por lo general de una hora. Se inició con dos salas conectadas, en una estaba el profesor y en la otra los alumnos. Ya ha comenzado la multiconferencia a través de un equipo especial "puente de multiconferencias". texto.

7.3.2. El libro multimedia es el heredero y superador del clásico libro de

Algunos lo confunden con el hipertexto, otros lo distinguen.

Se suele elaborar a partir de los libros impresos, introducidos en el ordenador, se le añade información audiovisual, se fragmenta en unidades (nodos o páginas) y se establecen índices que permitan explotarlo de un modo adecuado, no necesariamente linéal.

7.3.3. Redes de ordenadores. La base fue el Bulletin Board System (BBS) con un ordenador central al que se accede desde un computador que 
tiene un módem y usa la vía telefónica. En la conferencia por ordenador, un profesor desde el ordenador central dirige la clase.

La revolución informática se produce ante nuestros ojos, en la sociedad, pero apenas en las escuelas. Una nueva generación llega al Centro de enseñanza manejándolo, jugando con él, pero en muchos centros docentes seguimos con los apuntes y el libro de texto.

Hay que estudiar las posibilidades de una comunicación mediada por ordenador en un entorno abierto.

Radio, televisión o el libro son unidireccionales, pero Internet es bidireccional. Cualquiera puede ser emisor o receptor. Constantemente aparecen nuevas formas de comunicación, nuevas aplicaciones y herramientas. Se estima que cada mes aumentan en $10 \%$ los usuarios.

Comenio en su Didáctica magna en el siglo XVII decía que pretendía enseñar, todo, a todos, totalmente (omnia, omnes, omnino). Internet parece estar en condiciones de cumplir este sueño, al menos de ofrecer toda la información a todos sin restricciones de tiempo y lugar. De algún modo puede suplir la transmisión oral, el libro, la biblioteca y el museo.

La comunicación puede darse entre individuos y entre grupos, con todas las variantes, y ser sincrónica como la audio o la vídeo conferencia, o asincrónica como en el correo electrónico.

La mayor parte de estos servicios son interactivos frente a los tradicionales pasivos como la prensa, el libro, la radio o la televisión.

Entre 1980 y la actualidad ha habido progresos sorprendentes: videodiscos, laservisión, CD-ROM y pronto los DVD (Digital Video Disk), de indudable valor para el autoaprendizaje.

Conviene registrar que el aprendizaje se produce más que por el diseño del programa o por las virtualidades de la técnica, por lo que el estudiante hace con él.

\subsection{EL COMPUTADOR EN EL APRENDIZAJE ACTIVO}

El computador es la frontera tecnológica de más irreprimible expansión. Las ventas de ordenadores personales aumentaron en un 16 por ciento en todo el mundo, en el tercer trimestre de 1997. En todos los países se han multiplicado los proyectos y las inversiones multimillonarias porque estiman que es un instrumento indispensable para facilitar los aprendizajes y mejorar la calidad de la educación. En la Revista Comunidad Escolar (22-10-97) apa- 
rece en portada, en grandes caracteres, esta noticia: "El MEC invertirá más de 2.000 millones en la compra de ordenadores". El ordenador facilita el autoaprendizaje y pone en juego un rico abanico de actividades. Algunos se limitan a preguntar en los ejercicios de autoevaluación, otros simulan situaciones complejas que obligan a tomar decisiones. En la UNED española se han simulado las prácticas de laboratorio y han resultado tan eficaces como las reales.

Está probado su valor para aprender destrezas específicas sencillas (como el cálculo numérico) mediante la repetición. El ordenador tiene una paciencia infinita y detecta los errores inmediatamente. También se emplea en la resolución de problemas. Hay videojuegos educativos que se inspiran en situaciones de aprendizaje.

Algunos programas cumplen también la función tutorial. La Feruniversität alemana ha sido pionera en este campo.

Recordemos que la enseñanza programada ha tenido dos modelos clásicos: El lineal skinneriano y el ramificado o crowderiano. En este último la secuencialidad viene dada por el éxito o el fracaso en las respuestas. Se trata de una autoevaluación permanente. En un caso el alumno ha de formular la respuesta, en el otro basta con que reconozca, entre las opciones que se le ofrecen, la correcta.

En las simulaciones se pueden adquirir destrezas complejas y obligar a tomar decisiones.

Las nuevas tecnologías de la información no obtienen todo su valor formativo hasta ser integradas en un sistema tecnológico-pedagógico.

\subsection{AUTOPISTAS DE LA INFORMACIÓN. SU IMPACTO EN LA EDUCACIÓN}

Nacieron en compañías multinacionales. Son redes que conectan hogares, centros de enseñanza, empresas e instituciones que transfieren texto, voz e imágenes. Se proyecta que estos enlaces sean de banda ancha, por su alto rendimiento y su capacidad de transmitir todo tipo de información, lo que se consigue mediante tecnología de comprensión digital y por medios físicos como la fibra óptica.

Se habla de las autopistas de la información y hasta de superautopistas, quizá sea mejor hablar de crẹación de espacios o de comunidad de personas que se relacionan en espacios cibernéticos.

Las autopistas de la información permiten un aprendizaje activo, interactivo y cooperativo, sincrónico y asincrónico. Se ofrecen con este medio las 
mismas posibilidades de interacción que en el aula real, en la biblioteca o en la cafetería. Los alumnos pueden exponer y discutir sus trabajos. Cualquiera que tenga acceso a la red puede participar en los debates.

Hoy día tenemos: LAN, WAN, INTERNET, ARPANET, USENET Y BITNET, que han superado, con mucho, todas las previsiones.

\subsection{EL AULA VIRTUAL}

De las Autopistas de información destaca INTERNET (World Wide Web, WWW), la telaraña mundial. Cualquier ordenador puede conectarse con cualquier otro.

Cada vez se desarrolla más software para navegar por INTERNET.

Inconvenientes: lentitud en las horas punta y la información basura. En España se utiliza INFOVÍA de la C. Telefónica, como red de ordenadores conectados a ella y a INTERNET. (Utiliza el protocolo de comunicación TCP/IP). La ventaja es el bajo coste independientemente del lugar de la llamada.

La UNED accede a Internet a través de la Red IRIS. Todos los profesores pueden conectar con INTERNET por esta vía y los alumnos por sus propios medios. La dirección en Internet de la "home page" de la UNED, donde aparece la información general y por departamentos, es: http://WWW @ uned.es.

La UNED participa en proyectos europeos para investigar el desarrollo de la conferencia por ordenador en el aula o campus virtual. Hay en la UNED dos BBS destinados a la distribución de material de algunos cursos específicos. Anualmente realiza un "Congreso Internacional de Informática educativa" donde se recogen experiencias de todos los niveles educativos.

Existen espacios para la interactividad lúdica como MUD o el Internet Relay Chat (IRC). También para información, distribución y recuperación en cualquier formato digital World Wide Web (WWW) Gopher, File Transfert Protocol (FTP), que permiten crear comunidades virtuales que se comunican e interactúan en espacios cibernéticos, como en las listas de correo electrónico, que se relacionan como si se reunieran cara a cara, o constituyendo un aula virtual, o una biblioteca virtual, que facilita recursos para la enseñanza y el aprendizaje.

Una escuela remota puede convertirse en vecina y más aún integrarse en nuestra aula. Las tareas del profesor son similares a las que desempeña en el aula: prepara materiales, tutoriza, motiva, evalúa, dirige investigaciones. 
También se emplea en administración, para recoger y difundir la información y para la formación continua del profesorado.

El WWW permite el almacenamiento, búsqueda, análisis, tratamiento y recuperación de la información. En una reciente búsqueda sobre 'educación y valores' encontré, en el año 1995, en Yohoo, 1.144 .650 referencias (entrees).

Internet es el fenómeno sociológico más relevante de fin de siglo XX. Se habla del "ciberespacio" y de la "bitesfera", que han sobrepasado con mucho la aldea global de McLuhan, o el aula sin muros, con la enseñanza articulada en torno a las telecomunicaciones. Estas enlazan aulas en diversos lugares, o distribuyen cursos "on line" a los alumnos. Mediante las redes de aprendizaje colaborativo nace el "campus electrónico". Se forman redes de centros o consorcios, caracterizados por la modularidad e interconexión, que cumplen múltiples funciones: informan, entretienen, motivan, educan, imparten cursos regulares, se comparten experiencias, investigaciones, discusiones en grupo.

La información se presenta en forma de "nodos" o "pantalla" enlazados en forma de red. En cada nodo puede haber: imagen, voz, texto... Si la relación está definida por el texto se llama hipertexto, si lo está por el gráfico se denomina hipergráfico. Y se denomina hipermedia si integra ambos. Se selecciona lo que conviene o sencillamente se avanza página a página. Se puede "navegar" a través de los nodos y enlaces, por la red según deseos o necesidades del usuario.

\section{PROBLEMAS}

Uno de los principales problemas es que no se suele adaptar a las necesidades del usuario. ¿Se aumentarán las diferencias entre los informados y los que no lo están? ¿Es un derecho la información y por la tanto se convertirá en un servicio universal? Puede llevar a una profunda comunicación o a un control total, a la armonía global o a una invasión irrestricta de la intimidad.

Las cuestiones son tan novedosas como de difícil solución, pues carecemos de antecedentes y de seguros puntos de referencia, tales como: ¿Acceso a la privacidad de los contenidos? ¿Censura o no? ¿Disposiciones para los grupos menos favorecidos? Un tema fundamental es el de los costes, que deberían ser asequibles por tratarse de servicios universales. ¿Quién decide lo que puede o no aparecer? Por su instantaneidad no hay modo de censurarlo. Lo han empleado los terroristas o para la trata de blancas. La información privada de persona a persona no debería ser censurada, pero la pública no puede quedar a merced de lo que quieran hacer cualquier individuo o grupo irresponsable. ¿Qué pasa con el espionaje electrónico? 
Se habla de un aislamiento progresivo, pero el que podamos escuchar en un CD-ROM a los grandes maestros de la música no ha disminuido la presencia en los conciertos, ni que las obras maestras de los museos estén grabadas ha frenado la asistencia a ellos. Ha contribuido a popularizar el arte. Pero junto a las posibilidades técnicas será un factor decisivo nuestra capacidad creativa para llenar las nuevas tecnologías de la información de ricos contenidos culturales y penetrarlas de valores que hagan nuestro entorno y la vida más humanos.

\section{EL DESARROLLO DE LAS CAPACIDADES HUMANAS}

Los multimedia pondrán en juego nuevas capacidades cognitivas y metacognitivas. Lo que importa es aumentar el interés y la capacidad para que cada cual aprenda por sí mismo. La tecnología multiplica nuestras posibilidades, no resuelve lo que haremos con ella. Puede ser un instrumento de consumo pasivo o desplegar inéditas capacidades latentes. El gran objetivo de la educación contemporánea, aprender a aprender, ha encontrado en la telemática un nuevo sentido y un horizonte imprevisible para los que formularon tan ambicioso ideal. Reflexionar sobre los propios procesos mentales y de aprendizaje es lo que se designa como metacognición. Hay que conocer qué efectos producen los nuevos medios, qué estilos cognitivos exigen y desarrollan.

Cada sistema de símbolos desarrolla un tipo de capacidades, pero ahora se da la sinérgica integración de todos ellos. El auditivo, el activo, el visual o el abstracto, se ponen en juego simultáneamente.

Se dice que la falta de atención y el desinterés es el cáncer de la pedagogía y el mayor riesgo en el aprendizaje de las nuevas generaciones. Con las nuevas tecnologías de la información el panorama ha cambiado radicalmente. El niño puede estar escuchando o viendo la televisión y manipulando un CD-ROM sin pestañear durante horas.

La comprensión, retención, evocación y la transferencia de conocimientos, variará profundamente. El texto escrito requiere capacidades distintas a las que se emplean para interpretar imágenes o el lenguaje informático.

La motivación es un tema capital en el aprendizaje. No se puede enseñar lo que no se quiere aprender. El gran problema pedagógico era cómo motivar al alumno, pero los medios hoy le atraen y a veces le fascinan, estimulan variadas capacidades intelectuales, se adaptan mejor a todos los estilos cognitivos y permiten ver, siquiera sea en simulación, las aplicaciones de los conocimientos, que son siempre motivadoras. 
La telemática, por su enorme potencia y riqueza de materiales, puede ser altamente incentivadora o saturar y perturbar al estudiante. Se puede producir una cultura en mosaico -el "melting pot" de que se hablaba en la cultura americana, o de una cultura balcanizada. La mera interacción con los productos informáticos no garantiza el éxito del aprendizaje, si bien facilita, predispone y potencia nuestras capacidades.

Se habla de un modelo "alternativo" de aprendizaje, pero es preferible designarlo como "integrativo". Formar para un mundo tecnológico en una escuela desprovista de tecnología es una "contradictio in términis", pues la escuela debe preparar para el futuro que se avecina y forjar las nuevas generaciones para configurarlo en condiciones óptimas. En cualquier caso debe contribuir al desarrollo cognitivo, volitivo y afectivo.

¿Por qué usan tan pocos profesores las nuevas tecnologías de la información, a pesar de sus indudables y comprobadas ventajas? Ignoran cómo utilizarlas, cómo integrarlas en sus enseñanzas. A veces fallan las políticas educativas, cuando las nuevas tecnologías podrían contribuir a evitar el fracaso y aun la deserción escolar.

Ya hace decenios que se está intentando implantar el computador en el currículo de la educación primaria y secundaria. Entre nosotros, aparte de numerosas iniciativas de los centros, sobre todo de los privados, el proyecto Atenea, desde mediados de los años 80 , está generalizando su empleo escolar. Se necesita un software adecuado, con las guías para su explotación didáctica. Lo importante es estimular un pensamiento crítico, creativo, capacidad de generalización, de discriminación, una actitud activa y una autoevaluación permanente.

De muchos proyectos se dice que exigen más esfuerzo del previsto (preparación, compra de aparatos) y hay menos continuidad de la esperada. En general los docentes están poco entrenados, de modo que a mayor complejidad tecnológica menos uso y perseverancia Los aprendizajes con alta tecnología no siempre son superiores a otros que emplean técnicas tradicionales. La informática no es una asignatura que se haya cursado ni se suelen preparar los profesores, excepto los que estudian o explican informática.

No todos los alumnos tienen el mismo estilo ni ritmo de aprendizaje; el computador se adapta a los más variados estilos de aprendizaje, individualizando la enseñanza. Modifica el rol tradicional del profesor. Ahora, más que enseñar, asesora, refuerza, orienta y coordina los materiales. También el computador puede ejercer funciones tutoriales: comprueba el nivel de conocimientos, aplica simulaciones o la inteligencia artificial a programas educativos. El alumno se convierte en un autodidacta. El material informático se adapta a los distintos usuarios, es flexible, integrable con otros elementos, interactivo. Amplía conocimientos, no hay por qué restringirlo a lo que explica el profesor en el aula. 


\section{CALIDAD DEL MATERIAL}

Los criterios para distinguir la calidad de un material son: las ayudas que proporciona al educador y mejor aún al educando, y los niveles de aprendizaje que facilita, no la calidad formal u otros rasgos. De hecho, en los libros multimedia que se acercan más al libro tradicional, no pocos alumnos se suelen encontrar más a gusto que con los hipertextos, porque aquellos se aproximan más a sus hábitos tradicionales.

\section{LA NUEVA ÉTICA DE LA TELEINFORMÁTICA}

Surge una bandada de problemas axiológicos: la confidencialidad de la información, la protección de la infancia... La legislación, pensada para otras situaciones, nos sirve de poco.

¿Contribuirán las nuevas tecnologías a humanizar el mundo? Nadie como el médico puede curar, pero también es el que mejor sabe cómo matar. No todo lo que puede hacerse es sin más lícito. La prepotencia de los nuevos medios puede inducirnos al abuso. Todo puede ser motivo de una humanización más profunda o traer riesgos apocalípticos. "En la actualidad, varios países disponen ya de armas informáticas similares a las creadas por el Pentágono para sembrar el caos en territorio enemigo mediante el desplome de los ordenadores que controlan la Bolsa, las transacciones bancarias, las tarjetas de crédito, el tráfico aéreo, las redes de alta tensión, el sistema telefónico, las comunicaciones policiales, etc." ( $A B C, 27-10-97$, página 36$)$.

Todo esto entraña problemas éticos que van más allá del mero despliegue tecnológico. Es otra dimensión inevitable, que está en nuestra mano plantear y resolver.

Debemos cultivar en los jóvenes la visión de futuro. Uno de los procedimientos de formación moral más eficaces consiste en anticipar, valorar, reflexionar sobre las consecuencias de nuestros actos. De todo acto humano, hecho con conocimiento y voluntariedad, somos responsables, se nos puede imputar, tenemos que asumir sus consecuencias. Pero vivimos en una sociedad donde cada cual quiere ignorar sus responsabilidades. La culpa y, por lo tanto, la causa se atribuye a los demás y a lo demás. Del fracaso escolar son todos responsables, menos el estudiante. De las conductas desviadas, la sociedad, y del accidente de circulación siempre el otro. Si el médico no me restituye la salud, su culpa es patente, pues tengo derecho no sólo a la atención médica, sino a la salud y, si no gozo de ella, alguien es el culpable. Y en la primera oportunidad le demando.

La jungla del futuro con su maraña de problemas tecnológicos, políticos, éticos, sociales y culturales, ha de ser desvelada. Preparar para penetrar en esa selva es la primera exigencia de la educación. 
Los ataques a la tecnología se multiplican por los que quisieran volver al estado natural. Pero los males del abuso de la tecnología se curan no volviendo al pasado, sino usando bien la propia tecnología. El empleo egoísta de la técnica puede convertirse en un polvorín, pero renunciar a ella sería volver a condiciones inhumanas. Cuanto más poder mayor responsabilidad tenemos. Más que a un excesivo control, el mal uso de las autopistas de información se debe a la falta de control.

Se auguró que el famoso Oliver (On-Line Interactive Vicarious Expediter and Responder) (1968) tomaría nuestras decisiones más importantes. Es un ejemplo, no tan imaginario, del abandono de nuestro indelegable protagonismo. Ante cada innovación debemos preguntarnos ¿cuáles son sus consecuencias en el mundo de los valores? No se discute el descubrimiento sino su aplicación y difusión. Hay que estudiar las consecuencias de las nuevas tecnologías, establecer la legislación correspondiente, corregir los errores y asumir responsabilidades. Todo puede tener un impacto irreparable o aportar soluciones inéditas a nuestros problemas más graves. La ingeniería genética es un ejemplo espectacular.

Con INTERNET las predicciones sobre la desescolarización, de Ivan Ilich, Goodman, y Reimer en los años 70 (que parecían ácratas y levantaron oleadas de indignación) en parte se han cumplido. Pero la tecnología la explotan expertos en educación. Y su uso didáctico normalmente es mediado por los profesores.

Los lugares de aprendizaje se multiplican: escuela, hogar, sitio de trabajo o de recreo, viajando... La verdadera red la forman las personas unidas en instituciones, con vocación de formación, o de llevar a cabo una tarea, unidas por las telecomunicaciones. Estas son sólo canales, pero no responden del contenido. Como tampoco garantizan la calidad de los mensajes la imprenta, la radio o la Televisión.

El fácil acceso a la información no implica necesariamente educación. La enseñanza es activa o es ineficaz, lo que implica un mayor protagonismo por parte de los estudiantes.

Disponemos de recursos potencialmente ilimitados, y la primera obligación es prever sus consecuencias y emplearlas sólo para una vida más humana, de más calidad.

Gozamos de inmensas posibilidades, gracias a las nuevas tecnologías de la información, de poder y eficacia crecientes. Sentimos graves necesidades educativas, cuyas aspiraciones se superan de generación en generación. Debemos conjugar posibilidades y necesidades, y ofrecer a todos la educación como un bien y derecho universal. Pero esto obligará a drásticos cam- 
bios de actitud y a un compromiso exigente y permanente con el aprendizaje por parte de todos.

Tenemos las claves para diseñar la educación del futuro, su configuración real dependerá de nuestro talante y talento para conjugar sistémicamente las tendencias al alza y los valores emergentes.

\section{BIBLIOGRAFÍA}

ALONSO, C.M. y GALLEGO, D.J. (1993) Medios Audiovisuales y recursos didácticos en el nuevo enfoque de la educación. Madrid: Confederación de Centros de Enseñanza.

(1994) Tecnologías de la información y la comunicación. Madrid: Universidad Nacional de Educación a Distancia.

(1996) Informática Educativa 96. Madrid: UNED.

AVAKOV, R.M. (1978) Le futur de l'education et l' education du futur. Paris: Instituto Internacional de Planificación de la Educación (Unesco).

BANGEMANN, M. (1994) Europa y la sociedad global de la información. Recomendaciones al Consejo Europeo, Bruselas.

BELL, D. (1973) The Caming of PostIndustrial Society. New York: Basic Books. Versión Castellana de R. García y E. Gallego (1986) El advenimiento de la sociedad postindustrial. Madrid: Alianza Editorial.

BERGER, G. (1963) L' homme moderne et son education. París: PUF

BOTKIN, M., ELMANDJRA, M. y MALITZA, M.(1980) Aprender, horizonte sin límites (Informe del Club de Roma). Madrid: Santillana.

CASTELLS, M. (1989) The Informational City, Information Technology, Economic Restructuring and Urban-Regional Process. Versión Castellana de R. Quintana (1995) La ciudad informacional. Tecnologías de la información, reestructuración económica y el proce- so urbano-regional. Madrid: Alianza Editorial.

COMISIÓN EUROPEA (1995) Libro Blanco sobre la educación y la formación. Enseñar y aprender. Hacia la sociedad del conocimiento. Luxemburgo: Oficina de Publicaciones Oficiales de las Comunidades Europeas. (1996) Building the European Information Society for Us All. First Reflections of the High Level Group of Experts. Interim Report.

FUNDESCO (1987) Educar para el siglo XXI. Madrid.

GARCIA ARETIO, L. (1994) La Educación a Distancia Hoy. Madrid: UNED.

GENERALITAT VALENCIANA. IMPIVA. Universitat de València (1996) Jornadas: "Las Tecnologías de la Información como instrumento para la Formación Permanente: Nuevas perspectivas para la Formación Abierta y a Distancia".

GIOVANNOLI, R. (1991) La scienza della fantasciencia, Milano, Bompiani.

GRAU, J.E. (1995) Tecnología y Educación. Buenos Aires: Fundec.

GRÜNBERG, J.A. Profesores y computadores: una investigación sobre factores que afectan al uso de computadores en colegios secundarios. Montevideo: ORT Uruguay.

HARASIM, L., HILTZ, S., TELES, L., TUROFF, M. (1995) Learning Networks. Cambridge (Massachusetts): MIT Press.

IRDAC (1994) The Challenge to european education. Unlocking Europe's human 
potential. Comission of the European Communities.

JONES, A., KIRKWOOD, A., Y KIRKUP, G. (1992) Personal Computers for Distance Leaming. London: Chapman.

KAHN, H. y WEINER, A. (1967) The Year 2000. Nueva York: Macmillan.

MARABOTTO, M.I. y GRAU, J.E. (1991 y 1992) Hacia la informatización del aprendizaje. Tomos I y II. Buenos Aires: Fundec.

_._(1995) Multimedios y Educación. Buenos Aires: Fundec.

MARÍN IBÁÑEZ, R. (1979) Interdisciplinariedad y enseñanza en equipo. Madrid: Paraninfo.

___(1995) El sistema multimedia de la Educación a Distancia. Madrid: UNED.

MINISTERIO DE EDUCACIÓN Y CIENCIA (1989) Programa de nuevas tecnologias de la información y la comunicación (proyecto Atenea). Madrid: MEC.

MINISTERIO DE CULTURA, GENERALITAT DE CATALUÑA y otros (1992) Mente Global. Barcelona.

OCDE. (1972) L'interdisciplinarité. Paris.

REGGINI, H. (1988) Computadoras: ¿Creatividad o automatismo? Buenos Aires: Galápagos.

ROMOSZOWSKI, A.J. (1992) The selection and use of Instructional Media. London: Kogan Page.
ROSSELló, P. (1974) Teoría de las corrientes educativas. Barcelona: Promoción Cultural. Versión catalana: La teoría dels corrents educatius (1987) Barcelona: Diputació.

SANCHO, J.(coord) European Conference about Information Technology in Education: A Critical Insight. Proceedings. Barcelona: Congreso Europeo T.I.E.

TINBERGEN, J. y JENSEN, J. (1975) Prospectiva y futuro de la educación. Madrid: ICCE.

TOFFLER, A. El "shock" del futuro. Barcelona: Plaza y Janés.

UNESCO (1979-1980) Reflection on the Future Development of Education: A selective and annotated Bibliography. Paris (dos volúmenes).

Meeting of experts on the incorporation of science and technology in the primary school curriculum (Final report). Paris.

(1983) Technology Education as part of general education: a study based on a survey conducted in 37 countries. Paris.

(1984) Consultation meeting on pilot proyect "Technology in general education". Beijing. Final report. Paris. (1991) Innovaciones en la educación de ciencias y tecnología. Paris. ORCYT. (1997) Enseñanza abierta y a distancia. Perspectivas y Consideraciones politicas. Madrid: UNESCO/UNED.

\section{REVISTAS SOBRE PROSPECTIVA Y FUTUROLOGÍA}

Analyse et prévision. París.

Analysen und Prognossen. Berlín.

Futures. Surrey, Inglaterra.

Futuribili. Roma

Prospección Siglo XXI. Caracas

Prospective. París.

The futurist. Washington. 


\title{
RESUMEN
}

Para prever los rumbos de la educación en el siglo XXI, recurrimos a dos metodologías prospectivas: extrapolación de las tendencias actuales y los ideales que demandamos se cumplan en el futuro. El progreso tecnológico y la mundialización son tendencias al alza. El derecho universal a la educación y la igualdad de oportunidades son reclamados por todos. Un mundo en cambio acelerado exige la educación permanente. Para responder esa demanda acrecida de educación para todos a lo largo de toda la vida, se abren nuevas posibilidades, gracias al sistema multimedia de enseñanza a distancia, que goza de un desarrollo espectacular en todos los niveles y modalidades de la formación. Sin renunciar a los momentos de tutoria presencial, y al tradicional material impreso, se aprovechan las virtualidades formativas del teléfono, la radio, el vídeo, la televisión, la videoconferencia, y, de un modo especial, el computador. Este permite archivar y recuperar rápidamente una cantidad enorme de material educativo, pero sobre todo facilita el aprendizaje personal interactivo, individualizado y, a la vez, universal, rompiendo las barreras tempoespaciales y sociológicas de la enseñanza presencial.

Palabras clave: Prospectiva educativa. Método Delfos. Igualdad de oportunidades. Educación permanente. Sistemas multimedia de educación a distancia. Redes telemáticas. Aula virtual.

\begin{abstract}
There are two principal methods in the prospective: to project into the future the present tendencies and to stablish the ideals to build the future. The technological progress and the globalization are the two growing tendencies. All people ask for universal right of education and the equality of opportunities. The changing world demand permanent education. The multimedia system of education at distance in all levels of educational system allows to serve efficiently lifelong education for all people. Education at distance use printed materials, tutors, telephone, radio, television, but specially the computer that make easy to file and recuparate very quickly a big quantity of didactic materials and facilitate personnal interactive learning. At the same time teaching at distance brakes barriers of space, time and sociological that put limits to the traditional teaching.
\end{abstract}

Key words: Educational prospective. Delphi method. Equality of opportunities. Permanent education. Multimedia system of education at distance. Telematic nets. Virtual classroom. 